Predicting Time to Graduation in Engineering by Student Behavior and Gender

Dr. Christine Valle, Georgia Institute of Technology

Dr. John D. Leonard II, Georgia Institute of Technology 


\title{
Predicting Time to Graduation in Engineering by Student Behavior and Gender
}

\begin{abstract}
Our state, like many, is currently under pressure to reduce time to graduation of college students to satisfy various local, city and state stakeholders. As a consequence, we seek to develop a systematic method to take into account both good reasons for delaying graduation (such as spending a semester in a co-op or internship) and negative reasons (such as failing classes). We also want to quantify an estimate for the delay based on each experience. The hope is that this model helps inform the discussions in our institution's upper administration and state legislature regarding time to graduation.
\end{abstract}

This study looks at retention and graduation patterns in engineering by gender, seeking specifically to understand why students tend to take longer than the advertised 4 years to graduate, and focusing on one institution only. While much attention has been given in the past to the issues of retention of women and under-represented minorities in engineering, most analyses use data collected at multiple institutions (thus blending together results coming from vastly different campus cultures) and tend to focus on the experiences of those who graduate versus those who don't. In this work, we focus on why the students who do graduate usually take much longer than the four (4) years that are routinely advertised. This study follows in the footsteps of previous work.

\section{Introduction}

Retention of engineering undergraduate students is not a new research topic. As a persistent source of worry in industry, government and academe, low graduation rates of engineering students could damage the supremacy of the US in its technical prowess. If current trends continue, the country could potentially lose to other countries (such as China and India) in the numbers of qualified engineering graduates overall.

Another well-known issue with engineering is the field's persistent lack of diversity. Since engineering pervades every aspect of modern life, it is vital that engineering products and processes reflect the diversity of the population they aim to serve. Engineering products (such as, say, voice recognition devices) used by a highly diverse population should not be designed overwhelmingly by Caucasian males. In addition, the changing demographics of the US (the fact that the Caucasian population will be a minority in the next few decades) spell doom for engineering programs if the engineering community doesn't do a better job of attracting and retaining a more representative and diverse segment of the overall American population ${ }^{1}$.

In this work we define retention the customary way, that is, by the number of first-time, full-time students that graduate from the institution within 6 years. Much past research on retention has focused on students who leave engineering (so-called "non-persisters") and what caused their departure. For example, Marra et al. ${ }^{2}$ shows students of both genders tend to drop out of engineering primarily for two reasons: 1 ) the curriculum is too challenging and the quality of teaching too poor, and 2) students don't believe they belong. 
Ohland et al. ${ }^{3}$ present an extensive analysis of retention measures and student educational experiences at the undergraduate level, and for the first time uses a semester-level measure of retention (rather than year-level retention which is the overwhelming approach). His group uses the large, multi-institution dataset MIDFIELD (Multiple-Institution Database for Investigating Engineering Longitudinal Development) which contains records of over 75,000 students in engineering during the years of 1988 through 1998. Ohland and his colleagues ${ }^{3,4}$ found that in general, it is shown that paths of persistence are nonlinear, gendered and racialized, so that it's important to use multiple measures to assess retention when dealing with diverse populations of engineering students.

A frequent concern in most retention studies is that researchers must lump disparate populations together to achieve adequate statistical meaning - for example, looking at STEM (Science, Technology, Engineering and Mathematics) majors as a whole without differentiating between the disciplines, and/or lumping multiple institutions together. Even then, it has long been known that women studying engineering often suffer from a lack of peer support, role models, and adequate academic preparation, and these problems can cause these students to transfer out of engineering ${ }^{5-8}$.

Research also shows that women are more likely than men to report that teaching styles, subject matter relevance, and the culture of the discipline affect their retention and eventual completion of the degree ${ }^{9}$. They're also more likely to report that tutoring services are important to their academic success and ultimately, their retention (even controlling for academic preparation and race/ethnicity). In general, women find the classroom climate in engineering to be chillier than White men, and are less likely to work as a practicing engineer in industry, government, or nonprofit organization after graduation - though both effects are lessened significantly if the women engage in engineering clubs or programs supporting women engineering students such as SWE (Society of Women Engineers) or NSBE (National Society of Black Engineers). Multiple studies (by Marra and others) show that unlike men, women studying engineering tend to be better retained if the institution offers support such as strong ties to faculty and other students, tutoring, availability of numerous student clubs, and living/learning communities ${ }^{10,11,12}$.

Despite these complaints, multiple studies, such as Consentino et al. ${ }^{13}$ and Lord et al.${ }^{14}$ found that retention is not the primary reason for the low percentage of women in engineering, but rather, recruitment. That is, when women enter college intending to study engineering, they usually do eventually graduate with an engineering degree and don't transfer to a nonengineering field. However, very few female high school seniors do in fact choose engineering as a field of study in college.

Our study is different in that rather than focusing on persisters and non-persisters, we focus on persisters who take longer than 4 years to graduate. We are specifically interested in finding the causes for students' delay in their graduation, and whether these causes are good (gaining work experience through co-op and internships, for instance) or bad (failing classes and having to repeat them). We're also interested in quantifying the delay these causes produce, in semesters, per cause. Does co-oping delay graduation more than, say, getting a F? 
This study is motivated in large part by our state's legislature, which wants to tie our share of state financial support to our graduation times. If we can document that the longer times to graduation that we see in our students are caused by good reasons (better readiness for the workforce) rather than bad ones, we can make a strong case to the legislature stakeholders that our funding needs to be maintained.

At our institution, the Georgia Institute of Technology (GT), the graduation rate is significantly above the national average. For students of both genders, the 6-year graduation rate is above $85 \%$. Therefore, the issue is not persisters versus non-persisters for us.

Another unique feature of our study is that it's done at the institutional level. Our numbers of engineering students and graduates are large enough that they have statistical meaning without pooling them with other institutions. Therefore, we are truly comparing like behaviors, done in the same educational environment. This also provides a tremendous advantage in that the data is consistent, and mistakes are minimized. Multiple institutions often define things such as transfer credit or AP credit differently, which necessarily muddies the results of the analysis.

To gain this level of depth and accuracy in the data across institutions normally requires Deanlevel contacts to be made. We are very interested in expanding our work to other universities, should there be interest, now that the "proof of concept" has been established.

This paper is a follow-up on our prior work ${ }^{15}$ that presented demographics for the cohort of study (students who enrolled in the College of Engineering between 2000 and 2005 and have since overwhelmingly graduated, representing 6 years of complete data) and analyzed time to graduation in the following situations:

- Citizenship and residency status,

- Whether they were a student-athlete at any time during their studies,

- Whether they received a poor grade (D, F, or Withdrew), AP credit or transfer credit.

In this paper, we seek to expand the study to look at the impact of work experience (such as coop and internships), and changing majors or Colleges (not institutions as a whole - we're only considering persisters - but instead, transferring from, say, the College of Engineering to the College of Sciences). Ultimately, our goal is to present a statistical formula assessing and quantifying the delay these various behaviors cause on the student's time to graduation. This formula will be presented in future work.

Before we start presenting our analysis and results, we want to stress that we in no way claim that our conclusions can extend to other institutions. Our institution is pretty unique in its size, limited focus of degree offerings (we are not a comprehensive university) and selectivity. But we instead hope that our work will inspire others to conduct similar investigations at their institutions. Most of them (at least public, state-supported institutions) face the same accountability issues we have from our state, and it would be fascinating to see how the same student behavior (say, getting a failing grade and having to repeat a class) affects time to graduation across different institutions. 


\section{Analysis}

As mentioned previously, this paper looks at 6 cohorts of students, ranging from 2000 until 2005, enrolled at Georgia Tech (GT) within that window of time. Due to the difficulty of tracking transfer students, they are excluded from our analysis and we restricted ourselves to students admitted to GT in their $1^{\text {st }}$ year (first-time freshman students).

For this cohort, student subpopulation profile, such as grades, whether they ever were considered a student-athlete in their time at GT, "AP” (Advanced Placement) and transfer credit were all presented in our prior work and will not be reiterated here. Only basic demographics (gender and ethnicity) are included below for completeness.

\section{Student subpopulation profile}

Here are general counts on our population of interest:

Table 1 - Counts of female and male students in the College of Engineering at GT

\begin{tabular}{|l|r|r|r|r|r|r|r|}
\hline Gender & 2000 & 2001 & 2002 & 2003 & 2004 & 2005 & (All) \\
\hline M & 997 & 998 & 1080 & 1110 & 1275 & 1171 & 6631 \\
\hline F & 296 & 268 & 298 & 256 & 351 & 332 & 1801 \\
\hline (All) & 1293 & 1266 & 1378 & 1366 & 1626 & 1503 & 8432 \\
\hline
\end{tabular}

Next let's look at residency and citizenship for the entire population:

Table 2 - Counts of state residents, US residents and international students in the College of Engineering at GT

\begin{tabular}{|l|r|r|r|r|r|r|r|}
\hline Residency status & 2000 & 2001 & 2002 & 2003 & 2004 & 2005 & (All) \\
\hline $\begin{array}{l}\text { GT's state- } \\
\text { resident }\end{array}$ & 676 & 665 & 663 & 764 & 861 & 827 & 4456 \\
\hline US-resident & 554 & 560 & 654 & 529 & 696 & 626 & 3619 \\
\hline International & 63 & 41 & 61 & 73 & 69 & 50 & 357 \\
\hline (All) & 1293 & 1266 & 1378 & 1366 & 1626 & 1503 & 8432 \\
\hline
\end{tabular}

One can see that on average, the engineering student body at GT is about $53 \%$ from the state where GT is, and $47 \%$ from elsewhere, with only $4 \%$ international residents.

Next let's look at ethnicity and gender together: 
Table 3 - Counts of female and male students, by racial or ethnic group, in the College of Engineering at GT

\begin{tabular}{|l|r|r|r|l|l|r|l|l|l|}
\hline & $\begin{array}{l}\text { Asian } \\
\text { (Z) }\end{array}$ & $\begin{array}{l}\text { Black } \\
\text { (B) }\end{array}$ & $\begin{array}{l}\text { Foreign- } \\
\text { born }\end{array}$ & $\begin{array}{l}\text { Hispanic } \\
(\mathrm{H})\end{array}$ & $\begin{array}{l}\text { Native } \\
\text { American } \\
(\mathrm{I})\end{array}$ & $\begin{array}{l}\text { Two } \\
\text { or } \\
\text { more } \\
(\mathrm{T})\end{array}$ & $\begin{array}{l}\text { Unknown } \\
(\mathrm{U})\end{array}$ & $\begin{array}{l}\text { White } \\
\text { (W) }\end{array}$ & (All) \\
\hline M & 1003 & 288 & 298 & 250 & 7 & 109 & 28 & 4648 & 6631 \\
\hline F & 285 & 134 & 61 & 66 & 5 & 34 & 4 & 1212 & 1801 \\
\hline (All) & 1288 & 422 & 359 & 316 & 12 & 143 & 32 & 5860 & 8432 \\
\hline
\end{tabular}

Next we would like to present student behavior not explored in our prior work, specifically:

- the propensity of students to change majors and/or Colleges, and that decision's impact on their time to graduation,

- the propensity of students to participate in co-op semesters or internships, and that decision's impact on their time to graduation.

\subsection{Propensity of students to change majors and/or Colleges}

At our institution, 'College' refers to College of Engineering, Sciences, Business, etc. A student who changes Colleges is still enrolled at our institution.

First we see how many changed majors at least once during their time at GT - this does not differentiate between students who change majors but stay within engineering, from the students who change to a new major outside of engineering:

Table 4 - Numbers of engineering students who changed their major at least once

\begin{tabular}{|l|r|r|r|r|r|r|r|}
\hline Cohort & 2000 & 2001 & 2002 & 2003 & 2004 & 2005 & (all) \\
\hline Changed major & 585 & 656 & 631 & 754 & 804 & 698 & 4128 \\
\hline Didn’t change & 708 & 610 & 747 & 612 & 822 & 805 & 4304 \\
\hline (all) & 1293 & 1266 & 1378 & 1366 & 1626 & 1503 & 8432 \\
\hline
\end{tabular}

Clearly a tiny majority of students (51\%) never change their major, but the rest change it at least once during their time to graduation.

We also checked how many students change majors to one outside of engineering, but then potentially return and might leave again: 
Table 5 - Number of times a student changes out of engineering, but then potentially comes back and changes again

\begin{tabular}{|r|r|r|r|r|r|r|r|}
\hline $\begin{array}{l}\text { Number } \\
\text { of } \\
\text { changes }\end{array}$ & 2000 & 2001 & 2002 & 2003 & 2004 & 2005 & (all) \\
\hline 0 & 1010 & 981 & 1150 & 1085 & 1306 & 1222 & 6754 \\
\hline 1 & 250 & 255 & 201 & 246 & 287 & 239 & 1478 \\
\hline 2 & 28 & 21 & 24 & 30 & 27 & 35 & 165 \\
\hline 3 & 5 & 6 & 2 & 5 & 4 & 4 & 26 \\
\hline 4 & 0 & 3 & 1 & 0 & 2 & 3 & 9 \\
\hline (all) & 1293 & 1266 & 1378 & 1366 & 1626 & 1503 & 8432 \\
\hline
\end{tabular}

One can see some of our students change majors as many as 4 different times! To summarize, the next table shows how many changed out of the College of Engineering at least once:

Table 6 - Numbers of engineering students who changed out of the College of Engineering at least once

\begin{tabular}{|l|r|r|r|r|r|r|r|}
\hline Cohort & 2000 & 2001 & 2002 & 2003 & 2004 & 2005 & (all) \\
\hline New college & 283 & 285 & 228 & 281 & 320 & 281 & 1678 \\
\hline Stayed in COE & 1010 & 981 & 1150 & 1085 & 1306 & 1222 & 6754 \\
\hline (all) & 1293 & 1266 & 1378 & 1366 & 1626 & 1503 & 8432 \\
\hline
\end{tabular}

Overall, on average 19\% of our students change out of engineering at least once during their time at GT. We are currently conducting a much finer-grained analysis of why students switch majors, within and out of and back into engineering, which should yield useful data as to why students change majors.

\subsection{The co-operative (co-op) and internship programs}

GT has a very active, voluntary co-op program in which students commit to working for the same company for at least 3 semesters, alternating with school. It also has a strong internship program, where students work for a company for at least 1 semester (which can be a spring, summer or fall semester).

To aid in visualizing the results, "heat maps" have been used in Excel to best indicate the most important results, and in each case, have been constructed for an entire table's data (not row by row).

First we look at how many students within our population of interest engaged in at least 1 semester, or more, of work experience - either co-op or internship:

Table 7 - Numbers of students who participate in a given number of semesters of work experience 


\begin{tabular}{|r|r|r|r|r|r|r|r|}
\hline $\begin{array}{l}\text { Semesters } \\
\text { of work } \\
\text { experience }\end{array}$ & 2000 & 2001 & 2002 & 2003 & 2004 & 2005 & (all) \\
\hline 0 & 625 & 603 & 612 & 625 & 720 & 598 & 3783 \\
\hline 1 & 32 & 33 & 42 & 25 & 36 & 39 & 207 \\
\hline 2 & 71 & 75 & 75 & 51 & 59 & 71 & 402 \\
\hline 3 & 88 & 76 & 78 & 76 & 109 & 70 & 497 \\
\hline 4 & 91 & 104 & 90 & 110 & 129 & 129 & 653 \\
\hline 5 & 51 & 66 & 81 & 70 & 79 & 93 & 440 \\
\hline 6 & 44 & 36 & 62 & 69 & 81 & 61 & 353 \\
\hline 7 & 48 & 44 & 61 & 73 & 81 & 58 & 365 \\
\hline 8 & 62 & 60 & 70 & 69 & 85 & 108 & 454 \\
\hline 9 & 64 & 67 & 92 & 90 & 105 & 115 & 533 \\
\hline 10 & 56 & 54 & 62 & 58 & 69 & 91 & 390 \\
\hline 11 & 35 & 31 & 39 & 33 & 37 & 45 & 220 \\
\hline 12 & 19 & 9 & 10 & 8 & 22 & 18 & 86 \\
\hline 13 & 3 & 4 & 3 & 5 & 11 & 4 & 30 \\
\hline 14 & 2 & 3 & 1 & 2 & 3 & 1 & 12 \\
\hline 15 & 1 & 1 & 0 & 1 & 0 & 1 & 4 \\
\hline 16 & 1 & 0 & 0 & 0 & 0 & 1 & 2 \\
\hline 17 & 0 & 0 & 0 & 1 & 0 & 0 & 1 \\
\hline & 1293 & 1266 & 1378 & 1366 & 1626 & 1503 & 8432 \\
\hline
\end{tabular}

One can see that the majority of students who seek work experience while at GT, tend to do either 4 or 9 semesters of either co-op or internships. This corresponds to 1-2 full co-op rotations, with potentially 1 or 2 internships more.

This data can be presented visually with percentages (note the bigger vertical scale):

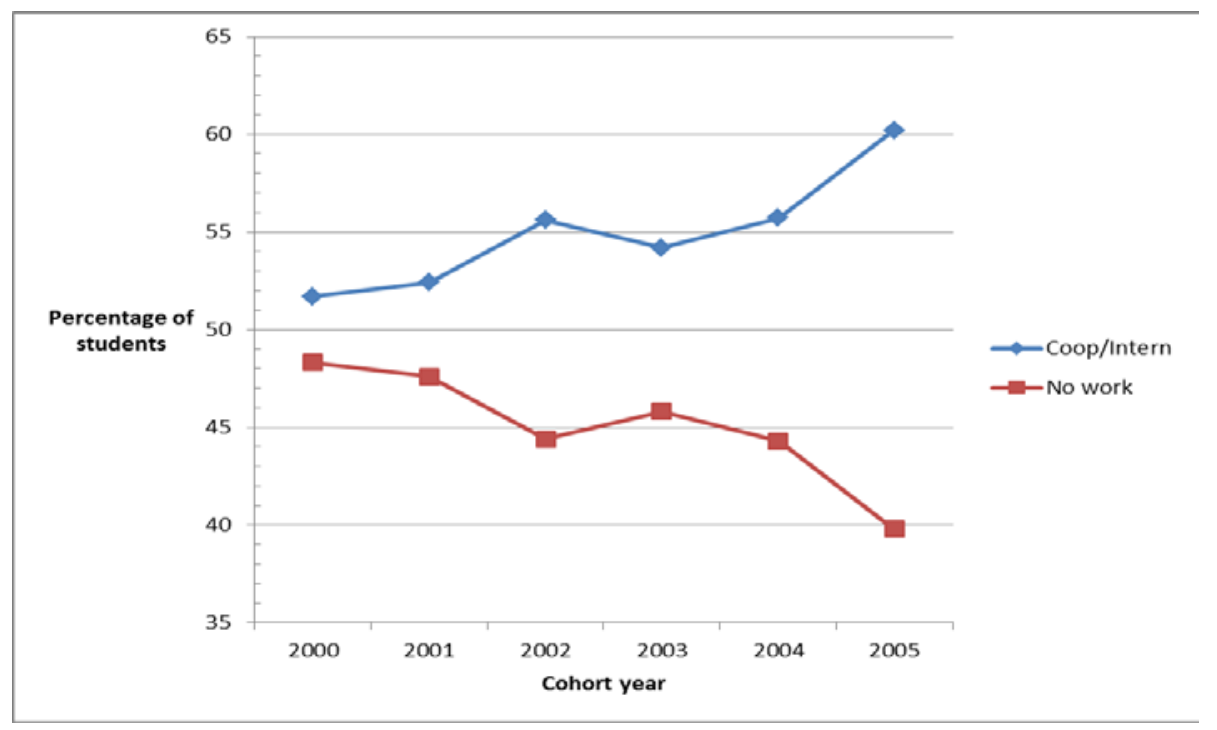


Figure 1 - Percentage of students, per cohort, who do at least 1 semester of work while at GT

We can see that as time went on, more and more students generally seek work experience, from a low of $52 \%$ in 2000 to a high of $60 \%$ in 2005 .

Finally, we looked at whether women and men pursued work experience as students differently:

Table 8 - Participation in work experience as a student, by gender:

\begin{tabular}{|l|r|r|r|}
\hline Gender & F & \multicolumn{1}{l|}{ M } & (all) \\
\hline Coop/Intern & 992 & 3657 & 4649 \\
\hline No work & 809 & 2974 & 3783 \\
\hline (all) & 1801 & 6631 & 8432 \\
\hline
\end{tabular}

One can see that about $55 \%$ of both female and male students gain at least 1 semester of work experience, so that both genders are equally interested in pursuing co-op and internship experiences.

\section{Exploring time to graduation (TTG) for the aforementioned behaviors}

Next we decided to analyze time to graduation based on elapsed numbers of terms, or semesters enrolled at school, versus the more commonly used number of years to graduation. For example, a student who graduates in a perfect 4 years, starting his or her freshman year in a fall semester and graduating in a spring semester, would be enrolled in 11 elapsed semesters: 3 (fall + spring + summer) for the $1^{\text {st }} 3$ years, then 2 for the final year (fall + spring), for a total of 11 terms of continuous enrollment, which represents $11 / 12 * 4=3.67$ years. A student graduating in what is considered to be 5 years would be enrolled in 14 elapsed semesters: 3 semesters (or terms) times 4 for the $1^{\text {st }} 4$ years, plus an additional 2 semesters, i.e. $14 / 15 * 5=4.67$ years.

Much of the data to be presented next can be displayed in a number of ways: by exact counts, by percentages, in tables and in graphs. Each technique has its advantages and disadvantages depending on the situation. When some counts are very low compared to others, percentages may show a distorted picture, and graphs may completely hide such features. As a result, we decided to present exact counts first, in tables, in most cases, and then percentages visually.

Previously we showed that the bulk of students graduate in either 11 (a "perfect" 4 years, with 4 Fall \& Spring semesters and 3 Summer semesters, corresponding to $1599 / 6885=23 \%$ of that population); 13 (which is slightly over 4 years, with an extra "normal" semester, such as Spring or Fall) for 1413/6885 = 20.5\%; or 14 (a "perfect" 5 years, without the last remaining Summer semester) for $1821 / 6885=26.4 \%$. We also showed that while the majority of students graduate in 14 or 13 terms, i.e. around 5 years of continuous enrollment, the majority of women graduate in a perfect 11 terms, compared to men (27.8\% versus $21.9 \%)$ whose majority graduates in 14 terms.

From this point on, we present tables of time to graduation with up to 18 or 20 semesters (20 represents a perfect 7 years, and numbers drop off sharply at that point since about $83 \%$ of students graduate by then). 


\subsection{Terms elapsed by changing majors}

Next we look at the impact of changing majors, whether the student stays in engineering or leaves for a different College, on the student's time to graduation.

\subsubsection{The new major is within the College of Engineering}

Next we look at time to graduation for students who changed majors at least once (but stayed in the College of Engineering), by gender, again truncated to 20 semesters since the data doesn't change much beyond that time:

Table 9 - Time to graduation of students (counts), by gender and whether they changed majors

\begin{tabular}{|l|l|r|r|r|r|r|r|r|r|r|r|r|r|r|r|}
\hline Gender & Changed major? & 7 & 8 & 9 & 10 & 11 & 12 & 13 & 14 & 15 & 16 & 17 & 18 & 19 & 20 \\
\hline F & Yes & 2 & 9 & 7 & 32 & 269 & 80 & 178 & 224 & 33 & 43 & 16 & 8 & 7 & 4 \\
\hline F & No & 0 & 5 & 9 & 19 & 162 & 61 & 134 & 179 & 27 & 23 & 9 & 4 & 2 & 1 \\
\hline M & Yes & 1 & 16 & 17 & 53 & 512 & 163 & 591 & 722 & 152 & 178 & 140 & 24 & 47 & 24 \\
\hline M & No & 5 & 53 & 28 & 90 & 656 & 125 & 510 & 696 & 166 & 184 & 93 & 20 & 19 & 26 \\
\hline (all) & (all) & 8 & 83 & 61 & 194 & 1599 & 429 & 1413 & 1821 & 378 & 428 & 258 & 56 & 75 & 55 \\
\hline
\end{tabular}

For the equivalent percentage representation:

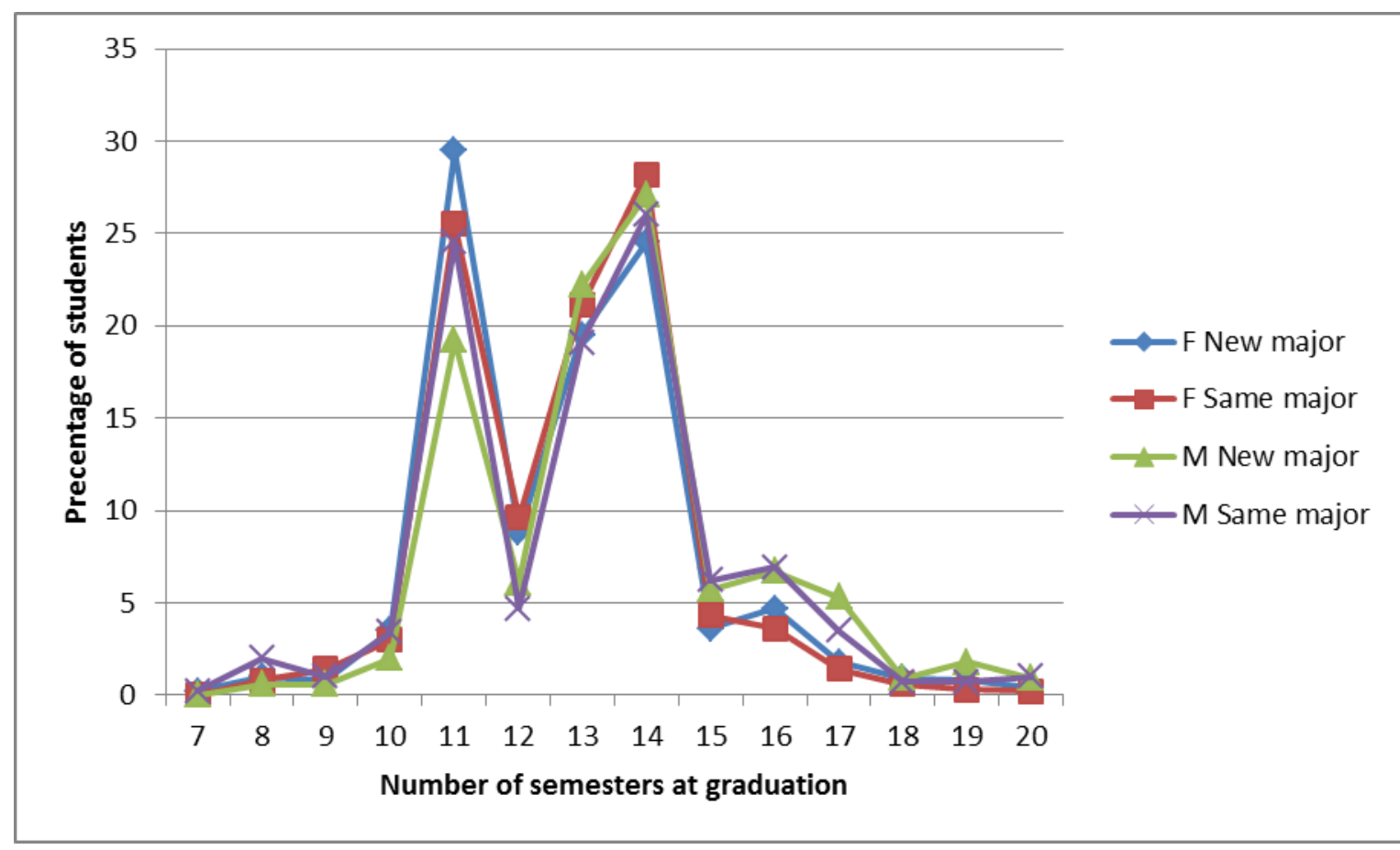

Figure 2 - Percentages of students vs. time to graduation, by gender and whether they changed majors

Changing majors doesn't seem to delay graduation much - the bulk of students still graduate in 11,13 or 14 semesters. Interestingly, women who change majors seem to graduate the fastest, since the largest group of them graduates in 11 semesters. Women who don't change majors 
graduate preferentially in 14 semesters, then 11 then 13 . For men, changing majors seems to delay graduation by overwhelmingly 3 semesters (11 to 14) then 2 to a lesser extent. Men who don't change majors graduate overwhelmingly in 14 semesters, then 11 then 13.

So for men, changing majors doesn't seem to markedly change time to graduation, which remains overwhelmingly at 14 semesters, but for women, it tends to accelerate it, from 14 to 11 ! For women, changing majors seems to improve their time to graduation! We suspect this could be due to a combination of increased motivation and interest in the new major, and the realization their change will affect their graduation time and thus a renewed focus on finishing as quickly as possible.

In general, the $1^{\text {st }} 2$ years of engineering study at GT are extremely similar (at most, the majors will differ by a maximum of 6 credit hours, i.e. 2 classes) so if students switch early on in their studies, the change in major will not greatly impact time to graduation. Currently we cannot analyze the data for when students made their $1^{\text {st }}$ switch, but we hope to for a future publication.

\subsubsection{The new major is in a new, non-engineering College (Computing, Sciences, Architecture, Liberal Arts, or Business)}

Next we perform the same analysis, but this time on students who changed to a new major outside of the College of Engineering altogether, first in terms of counts (again truncated to 20 semesters for readability). We choose to include this section as most of these students choose a STEM discipline after their switch out of Engineering (for example, biology). At GT, the nonSTEM Colleges (Business and Liberal Arts) host almost 3,000 students out of a total enrolled student body of over 21,000 students. Of those 21,000 students, over $60 \%$ are in the College of Engineering, so even those who leave Engineering altogether tend to stay in STEM disciplines.

Table 10 - Time to graduation of students (counts), by gender and whether they changed Colleges

\begin{tabular}{|l|l|l|r|r|r|r|r|r|r|r|r|r|r|r|r|}
\hline Gender & $\begin{array}{l}\text { Changed } \\
\text { College? }\end{array}$ & 7 & 8 & 9 & 10 & 11 & 12 & 13 & 14 & 15 & 16 & 17 & 18 & 19 & 20 \\
\hline F & Yes & 1 & 8 & 5 & 15 & 121 & 36 & 66 & 98 & 11 & 22 & 10 & 2 & 5 & 4 \\
\hline F & No & 1 & 6 & 11 & 36 & 310 & 105 & 246 & 305 & 49 & 44 & 15 & 10 & 4 & 1 \\
\hline M & Yes & 1 & 1 & 3 & 21 & 177 & 58 & 216 & 262 & 43 & 77 & 64 & 14 & 30 & 12 \\
\hline M & No & 5 & 68 & 42 & 122 & 991 & 230 & 885 & 1156 & 275 & 285 & 169 & 30 & 36 & 38 \\
\hline (all) & (all) & 8 & 83 & 61 & 194 & 1599 & 429 & 1413 & 1821 & 378 & 428 & 258 & 56 & 75 & 55 \\
\hline
\end{tabular}

Here's the equivalent analysis for percentages: 


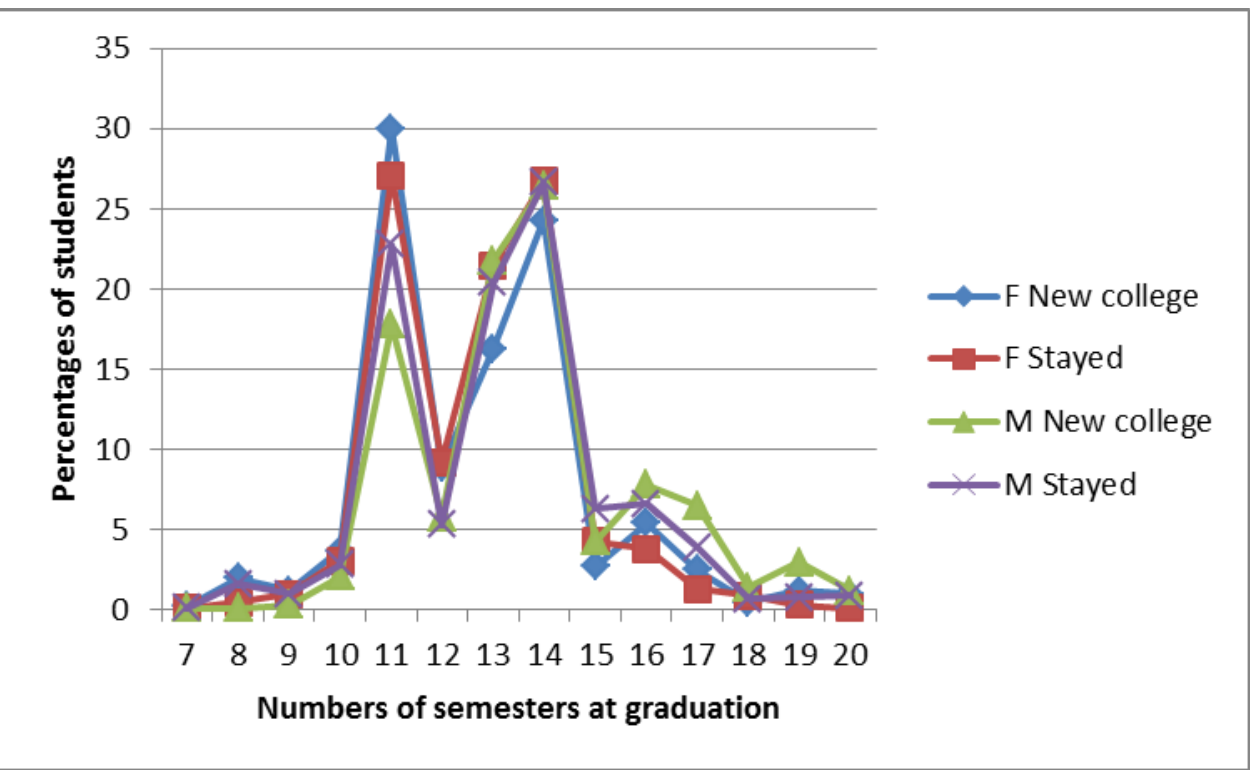

Figure 3 - Percentages of students vs. time to graduation, by gender and whether they changed Colleges

Again the bulk of students graduate in 11, 13 or 14 semesters. Whether women change colleges or not, they overwhelmingly graduate in 11 semesters, and changing colleges seems to accelerate that tendency. Men overwhelmingly graduate in 14 semesters in both cases, but for them changing colleges clearly delays graduation from 11 to 14 semesters. So changing colleges encourages early graduation for women but not for men.

\subsection{Terms elapsed by co-op code}

First we look at the total number of students who graduate in a given number of semesters of continuous enrollment, regardless of gender, and differentiate those who had at least 1 semester of work experience during their time as a student versus those who didn't (truncated to 18 semesters for readability):

Table 11 - Time to graduation of students based on how many semesters of work experience they gain while being students at GT

\begin{tabular}{|l|r|r|r|r|r|r|r|r|r|r|r|r|}
\hline $\begin{array}{l}\text { Time to } \\
\text { Graduation }\end{array}$ & 7 & 8 & 9 & 10 & 11 & 12 & 13 & 14 & 15 & 16 & 17 & 18 \\
\hline Coop/Intern & 1 & 39 & 24 & 88 & 754 & 223 & 817 & 1273 & 294 & 308 & 171 & 41 \\
\hline No work & 7 & 44 & 37 & 106 & 845 & 206 & 596 & 548 & 84 & 120 & 87 & 15 \\
\hline (all) & 8 & 83 & 61 & 194 & 1599 & 429 & 1413 & 1821 & 378 & 428 & 258 & 56 \\
\hline
\end{tabular}

One can see that among those students who have at least 1 semester of work experience, they overwhelmingly graduate in 5 "perfect” years (14 semesters), whereas those who don't overwhelmingly graduate in 4 "perfect" years (11 semesters). Predictably, working for a semester or more delays graduation.

Next we look at the influence of gender on this situation: 
Table 12 - Time to graduation of students based on how many semesters of work experience they gain while being students at GT, by gender

\begin{tabular}{|l|l|r|r|r|r|r|r|r|r|r|r|r|r|}
\hline Gender & Work? & 7 & 8 & 9 & 10 & 11 & 12 & 13 & 14 & 15 & 16 & 17 & 18 \\
\hline F & Yes & 0 & 7 & 2 & 25 & 197 & 75 & 184 & 289 & 45 & 43 & 17 & 8 \\
\hline F & No & 2 & 7 & 14 & 26 & 234 & 66 & 128 & 114 & 15 & 23 & 8 & 4 \\
\hline M & Yes & 1 & 32 & 22 & 63 & 557 & 148 & 633 & 984 & 249 & 265 & 154 & 33 \\
\hline M & No & 5 & 37 & 23 & 80 & 611 & 140 & 468 & 434 & 69 & 97 & 79 & 11 \\
\hline (all) & (all) & 8 & 83 & 61 & 194 & 1599 & 429 & 1413 & 1821 & 378 & 428 & 258 & 56 \\
\hline
\end{tabular}

This data can be presented using percentages:

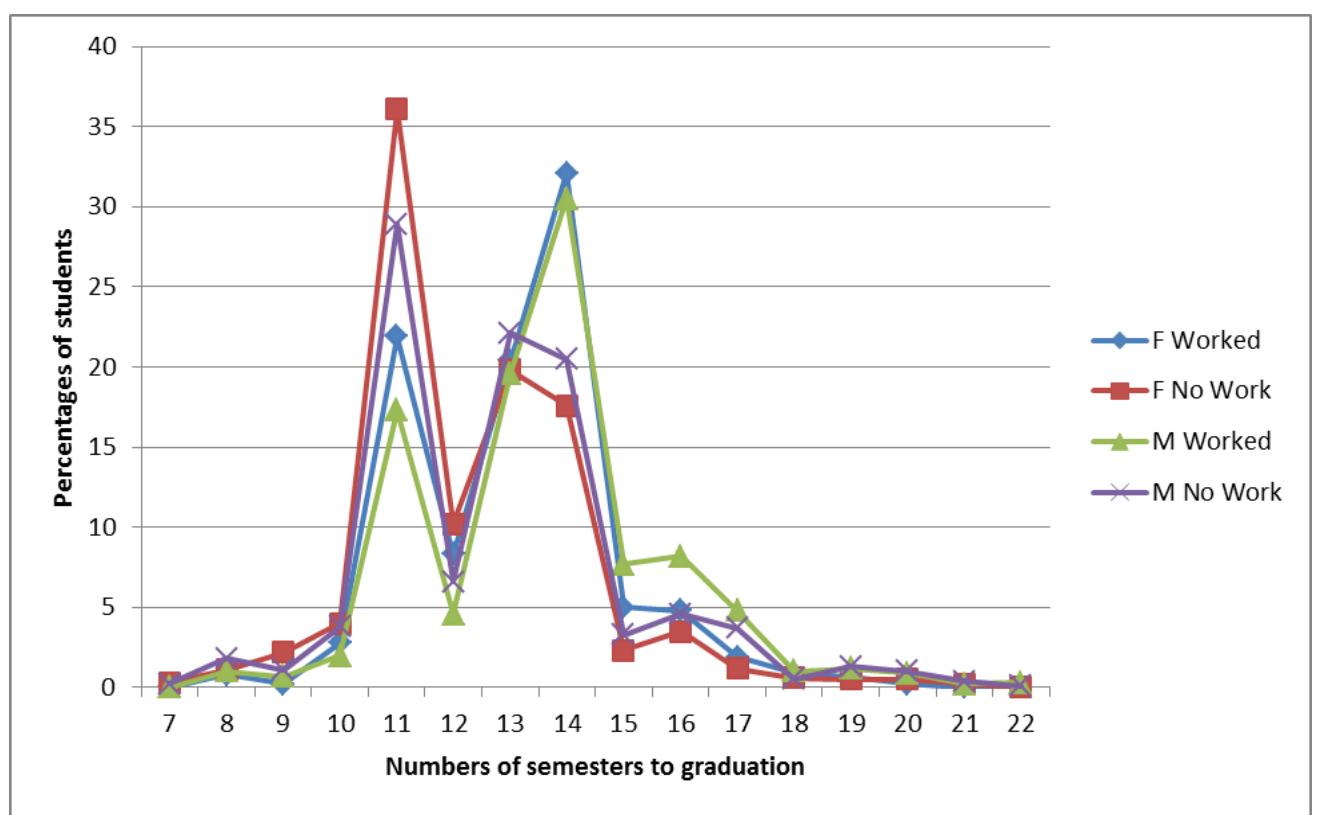

Figure 4 - Percentages of students versus their time to graduation, by gender and whether they gained work experience while at GT

Again, we can see that gender doesn't change things much at all - students who gain work experience while at GT overwhelmingly delay their graduation by at least 2 semesters.

\section{Predictive Model}

Next we seek to develop a statistical formula that will provide an estimate of a student's time to graduation, in semesters, based on whether the student engages in some of the behaviors analyzed in this paper and in our earlier work:

- Citizenship and residency status,

- Whether the student will be a student-athlete at any time during their studies,

- Whether s/he will receive a poor grade (D, F, or Withdrew), AP credit or transfer credit,

- Whether s/he will change majors and/or Colleges,

- Whether s/he will participate in co-op semesters or internships. 
The formula will take the student's gender into account and be based on a regression analysis. It will be presented in our future work.

\section{Conclusion}

In this work, we seek to identify the causes for most engineering graduates taking more than 4 years (11 semesters of continuous enrollment) to graduation, and whether these causes are good (gaining work experience through co-op and internships, for instance) or bad (failing classes and having to repeat them). We're also interested in quantifying the delay these causes produce, in semesters, per cause. This paper follows up on our prior work ${ }^{14}$ that presented demographics for the cohort of study (students who enrolled in the College of Engineering between 2000 and 2005 and have since overwhelmingly graduated, representing 6 years of complete data) and analyzed time to graduation in the following situations:

- Citizenship and residency status,

- Whether they were a student-athlete at any time during their studies,

- $\quad$ Whether they received a poor grade (D, F, or Withdrew), AP credit or transfer credit.

Predictably, we found the following results:

- Foreign-born students have the greatest likelihood of all to graduate in 11 semesters, rather than 14.

- Unsurprisingly, receiving AP credit and transferring credit helps students of both genders graduate faster.

- Conversely, being a student-athlete and receiving at least one D, F or W - all have a tendency to delay graduation, though the effect is much more pronounced for men than for women.

In this paper, we expanded the study to look at the impact of work experience while at school (such as co-op and internships), and changing majors or Colleges (not institutions as a whole we're only considering persisters - but instead, transferring from, say, the College of Engineering to the College of Sciences). We also seek to present a statistical formula assessing and quantifying the delay these various behaviors cause on the student's time to graduation.

We found that about half of our students change majors, sometimes out of Engineering altogether, at least once during their time at GT. Similarly, about half of them complete at least 1 semester of work experience while at GT, either in the co-op or internship program, evenly distributed between genders. For men, changing majors and/or Colleges either minimally affects time to graduation or delays it, but for women, changing seems to accelerate graduation. We attribute this to increased interest and motivation in the new major for women.

Gaining work experience while a student, however, clearly and predictably delays graduation time for both genders. The delay seems similar for both genders. 
We have yet to develop the predictive model at this stage and plan to present it in the final version of this work.

In future work, we also plan to look at ethnicity and race, and whether URMs also exhibit the same behavior as women and white men (we suspect that is not the case). We also plan to conduct interviews, both one-on-one and in focus groups, to better uncover the rationales behind these behaviors and results.

\section{Bibliography}

1. National Science Board’s 2014 "Science and Engineering Indicators”, http://www.nsf.gov/statistics/seind14/

2. Marra, R. M., Rodgers, K. A., Shen, D., Bogue, B., “Leaving Engineering: a Multi-Year Single Institution Study,” Journal of Engineering Education, 101(1), 6-17, 2012.

3. Ohland, M., Brawner, C., Camacho, M., Layton,R., Long, R., Lord, S., and Washburn, M., "Race, Gender and Measures of Success in Engineering Education," Journal of Engineering Education, 100(2), 225-246, 2011.

4. Ohland, M.W., Camacho, M., Layton, R., Lord, S., and Wasburn, M., "How we measure success makes a difference: Eight-semester persistence and graduation rates for female and male engineering students,” 2009 ASEE Annual Conference Proceedings.

5. Land of Plenty: Diversity as America's Competitive Edge in Science, Engineering and Technology, The Congressional Commission on the Advancement of Females and Minorities in Science and Engineering and Technology Development, Washington, D.C., 2000.

6. Women, Minorities, and Persons with Disability in Science and Engineering:2000, National Science Foundation, Arlington, VA, 2000 (NSF 00-327).

7. Adelman, C., Females and Men of the Engineering Path. A Model for Analysts of Undergraduate Careers, U.S. Department of Education, Office of Educational Research and Improvement, Washington, D.C.; U.S. Government Printing Office, 1998.

8. Seymour, E., and Hewitt, N.M., Talking about Leaving: Why Undergraduates Leave the Sciences, Westview Press, Boulder, CO, 1997.

9. Williams, F. M., Emerson, C. J., "Feedback Loops and Critical Mass: The Flow of Women into Science and Engineering," presented at Gender and Science and Technology (GSAT 10), Denmark, 2001.

10. Ro, H., Marra, R., Terenzini, P., Trautvetter, L., Walser, A., and Lord, S. "If You Build it, They Will Come (and Stay): Recruiting and Retaining Women and URM Students,” 2011 ASEE Annual Conference Proceedings.

11. Trautvetter, L., Marra, R., Lattuca, L., Piacentini, K., and Knight, D., "Programs and Practices Making a Difference: a Cross-Case Analysis Identifying Programs and Factors that Influence Recruitment and Retention of Women Engineering Students,” 2011 ASEE Annual Conference Proceedings. 
12. Gallaher, J., and Pearson, F., "Women’s Perceptions of the Climate in Engineering Technology Programs,” Journal of Engineering Education, 89, 309-314, 2000.

13. De Cohen, C. C., Deterding, N., "Widening the Net: National Estimates of Gender Disparities in Engineering,” Journal of Engineering Education, 98(3), 211-226, 2009.

14. Lord, S. M., Camacho, M. M., Layton, R. A., Long, R. A., Ohland, M. W., and Wasburn, M. H., "Who's Persisting in Engineering? A Comparative Analysis of Female and Male Asian, Black, Hispanic, Native American, and White Students," Journal of Women and Minorities in Science and Engineering, 15, 167-190, 2009.

15. Blasick, A., Valle, C. and Leonard, J.D., "Retention analysis of women engineering students,” ASEE Annual Conference Proceedings, 2012. 